\title{
Competition in Constructional Change
}

Welcome back to Ten Lectures on Diachronic Construction Grammar. In this lecture, I will continue with the general topic of constructional networks and the nature of the links between constructions and speakers' knowledge of language. In the last two lectures, I have talked about connectivity change. I have discussed the growth and the development of constructional networks, how they expand, how they contract, and how they shrink. I have reviewed different corpus-based methods that allow us to make observations about these processes, and I have explored what general conclusions we can draw from those observations with regard to proposals in grammaticalization theory and other frameworks. There is one kind of relation between constructions that I haven't discussed in depth so far. That relation would capture that two constructions are alternatives to each other. Some constructions have similar functions and they can be seen to be in mutual competition.

In this lecture, I want to explore the topic of competition in constructional change. Let us assume that two or more constructions have emerged as nodes in the constructional network. They have undergone constructionalization in Traugott and Trousdale's (2013) terms. They are connected with each other because they share part of their functional profile, perhaps even part of their form. They would constitute what is often called an alternation. That is a term that goes back to generative syntax and the idea of syntactic transformations. The implication at the time was that two members of an alternation, two member constructions would be seen as instantiating the same underlying structure. This would be illustrated for instance by the active voice, John drove the car, and the passive voice, The car was driven by John. The passive would be seen as a transformed variant of the active. This particular idea of transformations has fallen out of fashion. I have mentioned Goldberg's surface generalizations hypothesis (2002), which goes in the exact opposite direction by

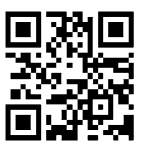

All original audio-recordings and other supplementary material, such as any hand-outs and powerpoint presentations for the lecture series, have been made available online and are referenced via unique Dor numbers on the website www.figshare.com. They may be accessed via this QR code and the following dynamic link: https://doi.org/10.6o84/mg.figshare.13691122. 
stating that surface form are important, not generalizations across alternating variants. It is however safe to say that despite all this, alternations have made something of a surprising comeback in recent years.

There is something very attractive and interesting about alternations, which are two ways of saying the same thing. You might wonder why languages afford this kind of luxury, to have two things for the same purpose. That is something worth thinking about. Personally, I wasn't drawn to this problem naturally, but I have been convinced that there is something to it and that there is something to be analyzed. I have been strongly influenced, for example, by the work of Benedikt Szmrecsanyi (2006), who I mentioned earlier today. He and his work have opened my eyes towards the intricacies of alternations, especially as we find them in English. We find them presumably in all kinds of languages, but there has been a tremendous amount of work on English.

I am going off script here, but I need to tell this little joke that I stole from Jack Dubois. Jack Dubois once opened a plenary talk that he gave with the sentence, "The study of language encompasses the fields of phonology, morphology, semantics, and the dative alteration." That is a quip, but there is some truth to it. The dative alternation is one of those pairs of constructions that have been studied extensively. There are of course other alternations in English. Besides the the dative alternation, there are the two genitives, i.e. the $s$-genitive and the of-genitive. There are two comparatives, i.e. prouder, the morphological variant and more proud, the periphrastic variant. The members of alternations are fruitfully analyzed in terms of competition between constructional variants. That is what I will be talking about in this lecture.

What I will have to say relates to basic idea \#1 that I presented in the very first lecture. The idea is that all of linguistic knowledge, according to Construction Grammar, is a network of form-meaning pairs and nothing else in addition. Competition in the network of constructions can be understood in terms of two nodes that are connected in the network. Competition arises if a speaker wants to express a particular meaning, and that meaning is connected to two different forms. Which form will the speaker choose? Given everything I have said so far about how the constructional network is organized, that would depend on the strength of the symbolic link between the meaning and one of the respective forms. The stronger connection wins and the weaker connection loses. We can further imagine a feedback mechanism that is activated when a construction is selected from the alternation. The winning connection might be rewarded and might be made even stronger, and the losing connection could be punished, so that it is even weaker than berfore. The next time the speaker wants to express that idea, any bias that was there in the first place would be even stronger the second time around. 
This is a question that has generated quite a bit of discussion. When one construction changes, what happens to other constructions that are connected to it? The common idea is that one construction's success leads more or less directly to the demise of another competing construction. This is very much the heritage of structuralist approaches. The underlying thought is that language change is systemic. We see a lot of evidence for that in sound change. The phonemic inventory of a language can be seen as a system where everything holds everything else in place. Construction Grammar has adopted the idea that constructions can be in competition if their meanings and functions are sufficiently similar.

There is a recent paper by Hendrik De Smet and colleagues (2018) from the University of Leuven that I would like to draw your attention to. It has been published in Cognitive Linguistics. In that paper, De Smet and colleagues comment on that particular idea:

The relation between functionally similar forms is often described in terms of competition. This leads to the expectation that over time only one form can survive (substitution), or each form must find its unique niche in functional space (differentiation).

This captures a broad implicit consensus in the field. However, De Smet and colleagues ultimately question this idea and propose a more nuanced perspective. I will come back to this tomorrow.

For now, let me just say that I have gone on the record with a somewhat noncanonical position with regard to this here. I have already shared that with you. In my book on constructional change, I have advanced the idea that "grammatical change is not a zero-sum game". I thought that slogan would catch on, but it didn't. Anyway, I had my doubts whether the adoption of new functions by one construction would necessarily drive out another construction that serves the same functions. When we look at languages, partial functional overlap is common, not rare. Inversely, we could say that there are phenomena such as polysemy. Polysemy is rampant. If we had perfect structural systems with one-to-one form-meaning correspondences where any expansion of meaning would lead to the retreat of another form, then that really shouldn't be there.

Another qualitative piece of evidence is that grammatical constructions tend to emerge in domains that are already relatively well represented by other constructions. Let me give you an example, English has nine core modal auxiliaries, and that constitutes a working grammatical paradigm. Yet, there are new modals that are coming into the grammar, forms such as got to or have to, which perform approximately the same function as forms that are already 
there. We already have must, why do we need got to? Why do we need have to? I do not think that competition can explain that. You need to make additional assumptions that explain why speakers start to use expressions like I have to go, but these assumptions are not predicted by competition.

Bill Croft has made a point that I see as compatible with my views here. He has argued that functional pressure, the kind of pressure that would bring constructions into competition, is not what drives competition between constructions. Functions are crucial, he says, when speakers innovate. Speakers are keen to express a certain idea. They're looking for new ways of expressing a given idea. This is what Croft (200o) calls "altered replication of linguistic forms". For example, they say I have to instead of I must. They say I am going to instead of I will. Competition happens in what Croft (2000) calls "propagation". An innovation is already there, propagation describes how it spreads through a community of speakers. Propagation, Croft (2000) argues, is not functionally motivated. It does not have anything to do with how well a form is functionally adapted or how useful its meaning is. Rather, Croft argues that it is socially motivated: "The basic mechanism for propagation is the speaker identifying with a social group". What I take away from this insight is that when we study constructional competition, it is very relevant to include social factors into our analysis.

In what follows, I would like to present to you a study of constructional competition from my 2013 book, in which I try to do that. Besides these theoretical considerations, studying competition also has some implications for methodology. I will be turning to a corpus-based method that moves away from collostructional analysis and the other types of analysis that I have been discussing up to this point.

How do we study competition? If we want to understand how competing forms develop over time, it would be good to have analytical methods that study processes of language change more comprehensively than just in terms of text frequency. Most of what I have discussed so far relies crucially on text frequency, but that is not all there is. The frequency of an item may stay constant, but it may still undergo interesting developments that merit our attention. Second, our methods should allow us to identify the explanatory factors that drove a linguistic change and when and why they did so. Also, the method should be able to distinguish between factors that are more important and less important or that exert less or more functional pressure. Lastly, our analysis should facilitate theoretical generalizations rather than just presenting us with single case studies or give us empirical facts.

In this lecture, I would like to present a case study of allomorphic change. This takes us from the verbal grammar that we looked at yesterday and the 
nominal grammar that we looked at this morning into a smaller level of linguistic organization. I want to focus on the development that happened to the English possessive determiners. Those are the words my and your in Present-day English. In the period of English that I am looking at, the Early Modern English period, several variants of these possessive determiners were in use. The first singular form was myne. Correspondingly, the second person there was thine, which begins with a voiced interdental. These forms are obsolete. If you do not recognize them, that is because you were born too late. These forms dropped their nasal final consonants, so they turned from myne and thine into my and thy. Thy corresponds what we now express as your, which came about through a further change that took place after the period that I am investigating here. I want to exemplify how diachronic corpus studies can usefully adopt methodologies that have been developed in Labovian American Variationist Sociolinguistics, which has a great deal to teach us in this context. I want to explain how change in allomorphy relates to the issue of competition in constructional change.

Let me start by discussing allomorphy. There are a few examples of allomorphy that students of English linguistics have to learn in their first introduction to the field. The phenomenon concerns phonemic variation between two or more realizations of the same morpheme. One of the examples that is often used to illustrate this is English plural allomorphy. We have ships with a voiceless /s/, we have harbors with a voiced /z/, and we have cruises with also a voiced /z/ that has a /o/ before it. Another type of allomorphy is apparent in the two indefinite determiners of English, so there is an /ən/ apple, there is a lə/ banana.

What conditions this variation? What causes speakers to choose one or the other? The variation between an /ən/ apple and a /ə/ banana, you know very well, is conditioned by the sound quality of the next element, i.e. the initial element of the noun. Allomorphy is often conditioned by phonological factors in this way. Typically, allomorphy is discussed in the context of grammatical morphemes. Allomorphy appears in the lexical domain in the phenomenon of stem allomorphy. Typically, speakers do not vary in their choices. We do not find English dialects in which the distribution of a / / / and an /ən/ is radically different than in others. That does not mean that there is no variation at all: Alternations such as dreamed and dreamt show competition between a regular variant and an irregular variant of a past tense form. The forms cannot and can't are variants that differ in terms of reduction. The variation between tom/ er/to and tom/a:/to is due to regional linguistic differences.

What I will be discussing in this lecture is a phenomenon that used to be variable, that used to have a number of different factors governing variation, 
but that eventually turned into a fixed state and the variability disappeared. Today, speakers do not say myne old friend any longer, instead they say my old friend. There was a time when it was possible to be linguistically progressive and say my old friend, and when you felt a little bit more conservative, you would say myne old friend. The same applies to the second person forms thine and thy.

Why now would it be advantageous to study allomorphic variation from a constructional perspective? A critic might object that formal variation that is not tied to any tangible meaning variation is in fact irrelevant to Construction Grammar, where we are concerned with form-meaning pairings. When we have two forms that map onto exactly the same meaning, that is not something that many constructional studies focus on. Myne and my definitely encode the same meaning. Furthermore, if not only the semantics but also the syntactic behavior of the allomorphs is nearly identical, then there would be little left to analyze from a constructional perspective. But contrary to that position, I would like to argue that the issue of allomorphy relates to the question of what a construction actually is, but let's move ahead and get to the actual analysis now.

The starting point of any analysis is of course the data. For this study. I used the Penn Parsed Corpora for Middle English and Early Modern English.

The phenomenon that I am interested in is the one of possessive determiners, the words myne and my, and thine and thy in front of a nominal, as in these examples here: with myne own eyes or the daies of my life. In the Penn Corpora, there is considerable variation with regard to possessive determiners. There is inter-speaker variation, so that different writers use them differently, but also intra-speaker variation, which means that the same writer uses sometimes this form and sometimes another. Many writers use both myne and my, that is, forms with the final nasal and forms without it. Sometimes they show a certain preference. One writer may have a preference for the conservative variant. Another may show a distribution that is more progressive. Is there an explanation for this variation? In fact, there is not only one explanation. There are many interlocking explanations.

Let me discuss some of the explanatory factors that I took into account. Trivially of course there is time. Later texts are more likely to contain the modern n-less variant, but there is the phonological context too. If the word directly following the possessive determiner begins in a consonant, as in my life, that would favor the n-less variant. Stress patterns play a role. When I say "That was not MY idea, that was HIS idea", that favors the n-less variant. It is a little tricky to extract stress patterns from writing, of course, at least this 
kind of contrastive stress, but there are well-conventionalized stress patterns of words that help us a little bit. There are also language-external factors that condition the variation. Women are known to be progressive across many linguistic changes, and this is no different here. When we look systematically at the gender of the authors, women can be seen to favor the progressive n-less variant. It has been proposed that formality plays a role, so that formal genres introduce a bias towards the $\mathrm{n}$-variant. Then there are frequent collocations such as myne own son, which would be my own son in modern English. Why should frequent collocations be less progressive? We know from other studies that chunks, frequent collocations, are conservative. They are produced very often together. Within a strong collocation, within a chunk, an old variant has a stronger chance of survival. You see this in some idioms and in some expressions that preserve sort of old syntax or old morphology. Shakespeare could write "I know not" instead of "I do not know". We still have that syntax in idioms like I kid you not, where we have the ancient pattern of negation. You can't do that with other verbs or with expressions that are not idiomatic in any way.

In the following, I want to address three questions. First, which of the proposed factors have a reliable effect on the choice between myne or my? Second, did the effects stay constant over time or did they change? Third, did myne and thine change in the same way at the same time, or would we be forced to say that they follow different trajectories? That is important to find out because we want to know whether speakers have formed a single generalization for all of these forms, or whether there is a separate generalization for myne and another one for thine.

I will start with the first question here, which of these factors have a reliable effect? For that, relied on some help from variationist sociolinguistic approaches, which have long been concerned with exactly this problem. There has been a focus on alternative expressions. Take for instance the quotative be like that I have mentioned already a couple of times in this lecture series. When you quote someone else's speech, you could say "He was like that is great", or you say "He said that is great". Social factors can explain to some extent whether you choose one or the other. The lesson that many sociolinguistic studies have taught us is that speakers' choices tend to be governed by probabilistic explanatory factors. In the case of the choice between the two genitives, i.e. the $s$-genitive and the of-genitive, maybe the most important determining factors are not social but rather language-internal, including semantic factors such as the animacy of referents. There are syntactic considerations, so constituent length plays a role, speakers are generally more likely to place long constituents towards the end of an utterance, at least in svo languages such as 
English. There are differences between different text types, and there is a host of other extra-linguistic factors like age, gender, the speech situation and so on and so forth.

In the database of examples that I used for this study, we find examples such as the daies of my life. What can we do with that? We can actually determine the relative frequencies of my and myne in different contexts. Then we ask how likely the use of the n-less variant is in this case, given that we have a text that was written in the year 1564 , given that the next word starts with a consonant, life, the writer is male and the text is from an informal genre.

Given all of these factors and all these variables and their levels, how likely is this outcome of the progressive n-less variant? This is very much a standard procedure that has been established in sociolinguistic multivariate studies. By now there is also a sizable literature that applies logistic regression methods to morphosyntactic variation.

Turning now to the second question, did the effects of the involved factors stay constant over time, or did they change? We know that the variation between myne and my was transient. Today, myne only survives in deliberate anachronisms, which means that factors that once triggered the use of myne are no longer effective today. You no longer know about this form. The system has turned from a network of probabilistic competing factors into a fixed system where everything is discrete. The analysis of changing effects is something that is a little trickier to analyze, and yet it very much describes a well-attested scenario of language change.

For example, historical studies show changing impacts of explanatory factors. Again, I am coming to Benedikt Szmrecsanyi and his work here. Together with other colleagues (Wolk et al. 2013), he has documented changing patterns of varition in the English s-genitive, as in my brother's car. That construction used to be very strongly restricted to animate possessors, but that restriction has loosened. Today we can say the company's car or the university's policy. The effect strength of animacy has changed over time. For earlier speakers, animacy was a strongly determining factor, and for present-day speaker, that effect has become weaker.

Then we have apparent-time studies showing different impacts for different age groups. Again, let me take the example of be like, which is preferred by female speakers, but most strongly by adolescent female speakers. There is an effect strength of gender that interacts with age. Speakers use this form specifically if they are young and female. We can establish that the processes of language change involve change in the ecology of conditioning factors. Some factors become more important, others may fade away and then cease to be important. Entire domains of variation may eventually become fixed and 
fossilized. I would like to argue that diachronic corpus linguistics can offer a contribution to the study of such phenomena.

Before we get to the actual analysis, I still need to briefly talk about the third question, namely, did myne and thine change in the same way at the same time? Why is this question important? If the two forms change in different ways, that would be evidence for the idea that myne and thine each formed a generalization of their own. Hence, the two would be different, if of course related, constructions. What the question boils down to is whether we are dealing with one constructional change or in fact with two constructional changes that happen simultaneously.

With all of these in mind, how did myne and thine change to my and thy?

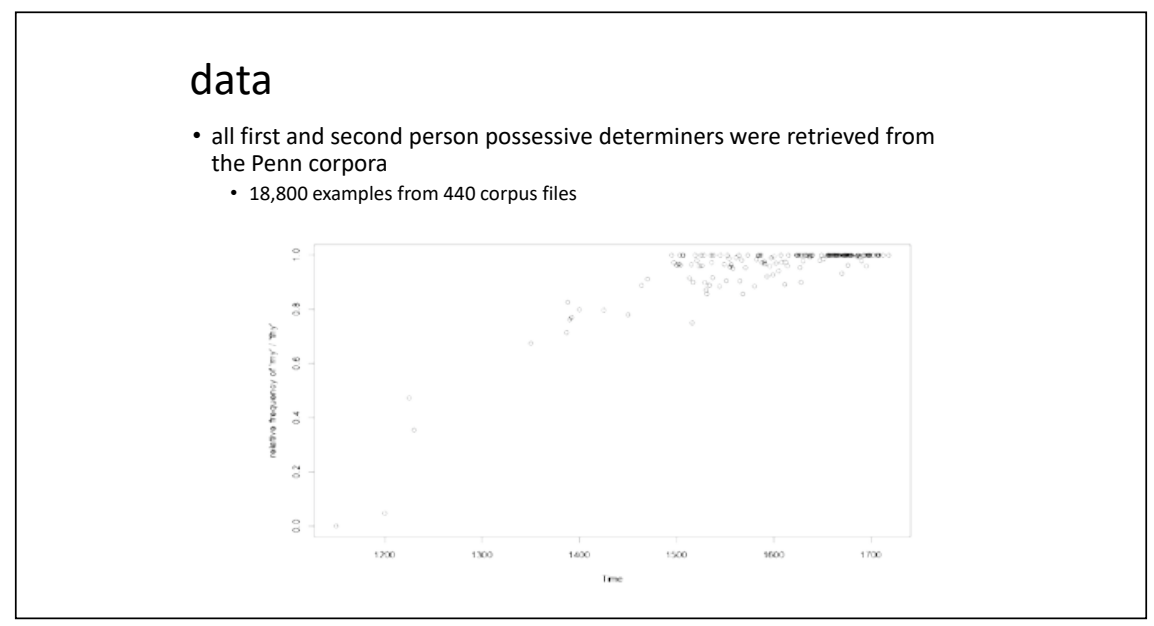

FIGURE 1

Here you see a graph with what sociolinguistics call an s-curve. You see the relative frequencies of the new n-less variant pooled for all corpus files of the same year. The higher a point is on the graph, the closer the data is to presentday usage. You see that the scale on the $y$ axis goes from $o$ to 1 . The value $o$ means all writers use the old variant, 1 means all writers use the new variant exclusively. It is plain to see here that there is much more data for the final two centuries than for the previous ones. We know more about the final stages of the development than we know about the earlier stages. But all in all, the $s$-pattern is fairly clear. Of course we know more about the data than just relative frequencies. All examples that I found in the data, all in all some 18,800 examples, were annotated for the explanatory factors that I discussed earlier. The data points you see on this slide come from 440 different corpus files, and every corpus file has the potential to show some intra-speaker variation. 
The examples were annotated for eight variables. Let me anticipate a question: Why were these variables chosen and not others? The answer is that I took six of these variables from the existing literature, which had identified them as relevant. To that, I added two other variables that I considered to be important.

The first variable concerns the phonological environment. Does the word after my or thy or myne or thine begin with a consonant? Does it begin with a vowel or does it begin with an $\mathrm{H}$ ? $\mathrm{H}$ is used as a third category here because there is variation in the way it is pronounced. Sometimes it is more vocalic, sometimes it is more glottal. We can assume that uses before $\mathrm{H}$ will exhibit a mixed profile.

I already mentioned stress, so for the second variable I took the stress pattern of the following word and annotated if the first syllable was stressed or not. English is a stress-timed language, so words have conventional stress patterns. It is uniVERsity / juini'v3:səti/, not UNIversity/'ju:niv3:səti/.

Another variable distinguished between first and second grammatical person. Do we have a first-person form like my? Or do we have a second person like thy?

I distinguished two levels of formality. Formal genres included texts from the Bible and law texts. Informal genres were personal letters or comedy texts.

Then is the gender of the writer. Are we looking at a text written by a male speaker, a female speaker or is the gender of the writer unknown? In historical documents, that is quite often the case. Another complicating factor is that many texts were actually written by scribes. Speakers are often nobility who would dictate their letters to scribes who wrote them down. We know from other research that these scribes didn't impose too much of their own preferences on those documents, but they were fairly faithful to whatever it was that the original writer of the letter said.

Now, on to the variables that I included, but that are new to this particular phenomenon. One variable I included is priming. If we look at the previous left context in the text, the previous 50 words, do we have an instance of myne or thine or my or thy in that context? If that is so, then there are reasons to think that the writer will be influenced. If a form is still activated, that would make it more likely that a writer will choose the same variant again.

The next variable concerns the relative frequency of the following element. There are some expressions that occur very often in the data that I analyzed. An expression such as myne own for example occurs very frequently. There is abundant evidence that increased frequency of a linguistic item leads to conservative behavior. Since myne own is produced and processed as a holistic unit, speakers are reluctant to switch to my own, even if they do so with other less frequent collocates. 


\section{phonological environment}

FIGURE 2

Let's now look at all of these variables and let's see how their impact may have changed over time. This graph shows the s-curve that you saw earlier with the raw data, but here we see it split up for the three different levels of the variable of the phonological environment. Three s-curves, one for possessive determiners that appear before a consonant, before an $\mathrm{H}$ and before a vowel. Again, the higher the data point, the higher the proportion of my instead of myne. What you can see in this graph is that the three curves start at different points in time and get to the final destination earlier than others. The effect of the phonological environment thus has a temporal contour. The switch from myne to my starts in pre-consonantal environments, like my life. Possessive determinants before $\mathrm{H}$ as in my head and before vowels, my own, remain on a low level until very late. The curve for the preconsonantal environment starts out in the very beginning, while the others continue to stay low. The difference is largest in period 5 , close to the end, and the others catch up after that.

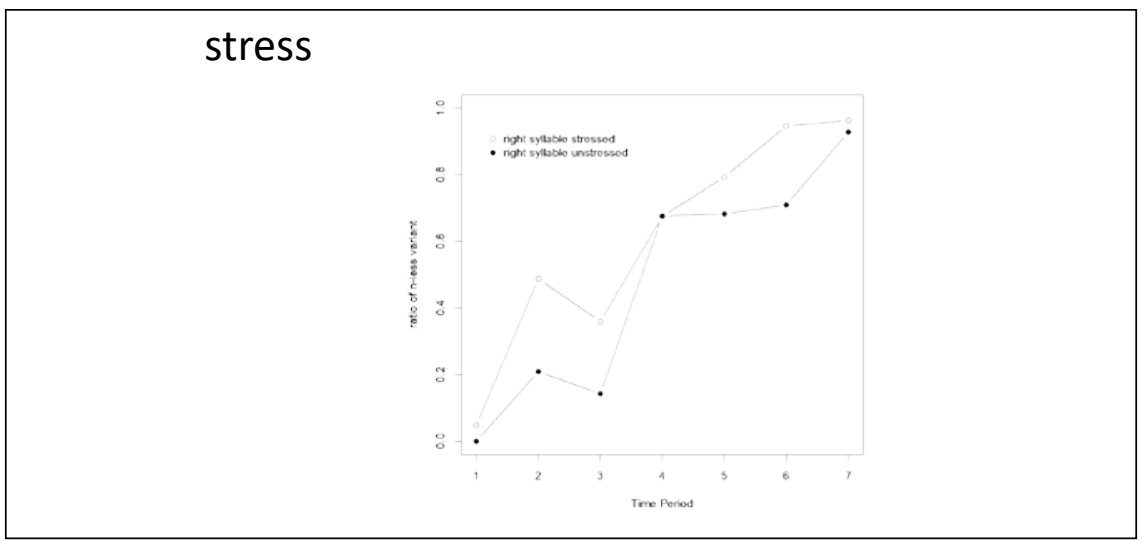


Let's move on to stress. In this graph, we see that the factor of stress on the falling syllable has a clear effect, so the n-less variant is more frequent in pre-stress environment, that is with expressions such as my father as opposed to my idea. But also here, the effect is not equally strong across all periods. In periods 1, 4 and 7, there is practically no difference. The effect is not completely uniform.

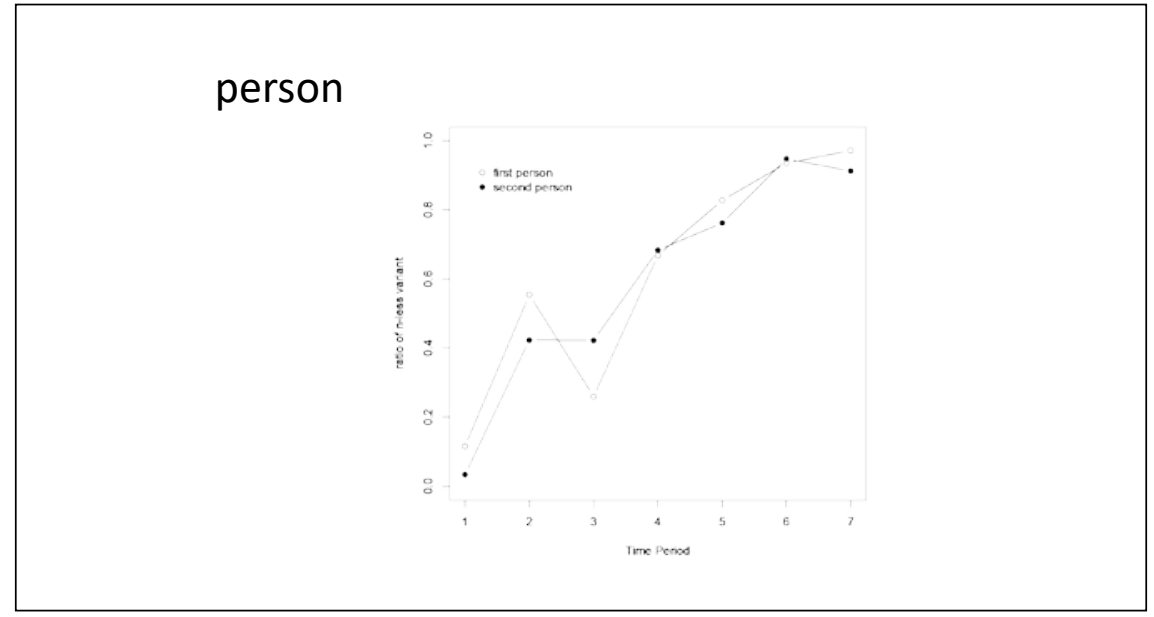

FIGURE 4

With the variable of grammatical person, we hardly see a difference. That is quite noteworthy. If we discard period 3 , which shows a little difference, then we could say that on the whole, first person forms are a little bit in the lead. First person forms are the white circles here. My is leading the way for thy, but yet it looks as though the developments from myne to my and from thine to thy proceeded very much in lock step, presumably because they are phonologically very similar. Speakers form a generalization across myne and thine, so that in contexts appropriate for $m y$, they were also deemed to be suitable for thine. I will come back to this later in this lecture.

Here's formality. Formality has been argued to be a conditioning factor for the older n-variant. The Penn Corpora actually do not confirm this idea. You see that the two curves are not distinguishable from one another. Very likely, there is no effect here, not even a transient one.

What about gender? Here you see a problem, namely that in historical documents, the gender of the writer often cannot be known with certainty. The only reliable data we have is from the last three corpus periods. Reassuringly, in those three periods, female writers are the black dots, they are highest up. They are in the lead. Males are the most conservative. Males are the empty circles here. We have the unknown gender writers in the middle of them. Even though 


\section{formality}

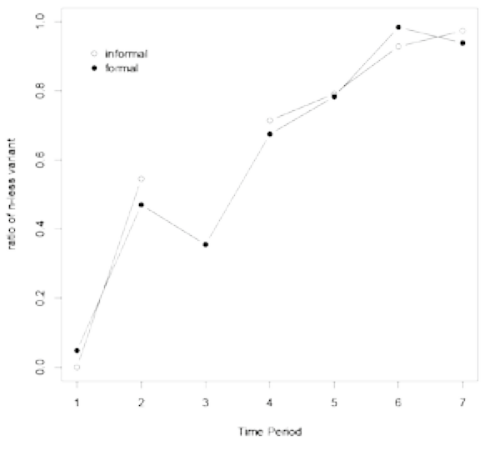

\section{gender}

FIGURE 6

the data is patchy, as I am ready to admit, I would go out on a limb and say that there probably is a small effect of gender.

Human language users are creatures of habit. If they use a form once, they are likely to use it again. This graph shows you that the n-less variant is indeed more frequent if it has been preceded by another n-less variant. Again, the only exception to this tendency is period 3. You see here, the lines cross and re-cross again. That might be an oddity in the data. Period 3 is actually something of an outlier here in this data.

So far, we've covered phonology, stress, person formality, gender and priming, we are still missing frequency. For that, I would like to show you a graph that may look a little strange at first. 


\section{priming}

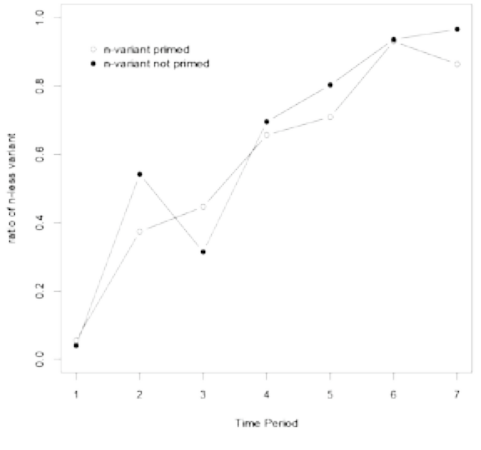

\section{right collocate frequency}

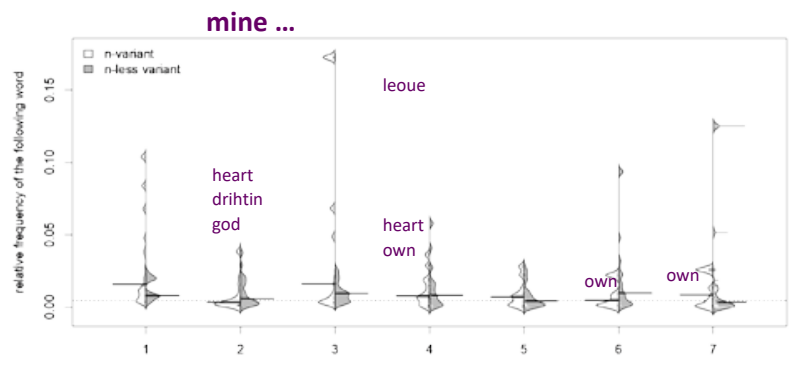

FIGURE 8

What you see in this graph are again the seven corpus periods. For each period, you see uses of the n-variant in white and uses of the n-less variant in grey. There are wavy patterns to the left and right in each section of the plot. Those are frequency distributions of the right side collocate. The interesting pieces of information are the little bumps that you see high up on the graph. Those are collocates that appear with high relative frequency in the respective periods with myne and my. My hypothesis was that the n-variant would show a preference for high frequency items, because high frequency chunks would be stored as single units, so they would be conservative. I expected myne to appear a lot with very frequent items. A pairing like myne own illustrates this. The little bumps in white, on the left-hand side of each line are in line with 
that prediction. However, high-frequency collocates are not restricted to the n-variant. Frequent items with my appear as well, which is the opposite of what I predicted. Let me show you the actual words that correspond to the bumps. In the early periods, high-frequency collocations include myne heart or myne god. In period 3, we have myne love, which translates as my dear, a term of address. In later periods, we have mine own in period 6 and 7 .

\section{right collocate frequency}

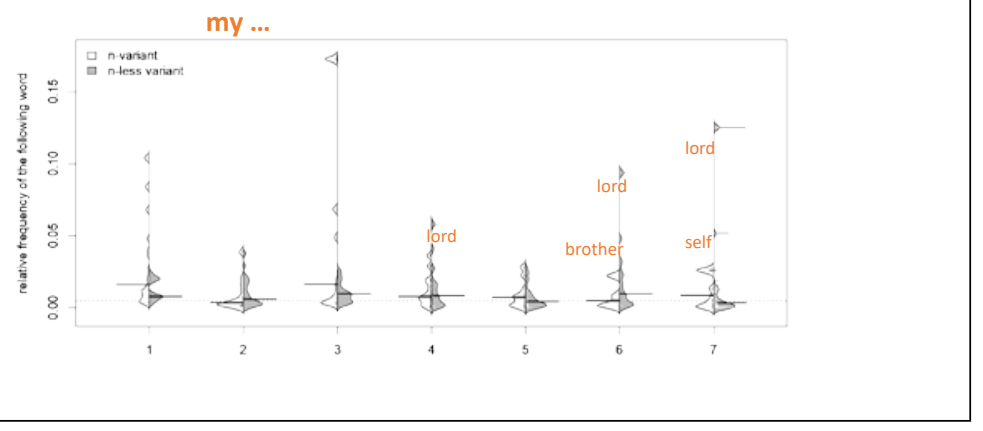

FIGURE 9

Conversely, if we look at the frequent collocations with $m y$, we see that the n-less variant has also a good number of chunks and most prominently so in the last period. Here we would have expected greater numbers of low frequency items. Again, frequency has an effect, but the effect is inconsistent. This suggests that my initial hypothesis was too naive.

Let me summarize what I have said so far. The n-less variant is increasingly more frequent in later periods. With regard to the following segment, the n-less variant originates in pre-consonantal environments and then spreads to prevowel and pre-H. As for stress, the n-less old variant is more frequent before stressed syllables. With regard to person, the n-less variant is a tiny bit more frequent in the first person. With regard to gender, the n-less variant is a little more frequent in texts of female writers. I didn't find any consistent effect of formality. There is a small effect of priming. Collocate frequency does not show a consistent effect. There is something going on, but it is not clear what. Knowing all of this is a good start, but the impact of different variables across time is only one part of the story.

The piece that is still missing concerns the third question. Did myne and thine change in the same way? We've seen that they change roughly at the same time, but how similar or how different are they with regard to their 
conditioning variables? If there are differences, this would suggest that there are two changes taking place and not just one. Let's take a look.

On the following slides, you will see a number of so-called mosaic arrangements. One for first-person, forms on the left, and one for second-person, forms on the right. For the n-less variant forms $M Y$ and $T H Y$, they are shown in the lower half. The n-variant forms are shown at the top. Overall you see that the modern n-less forms are overall more frequent in the corpus than the old $\mathrm{n}$-variant forms. You also see that in the second-person mosaic, there are relatively more n-variant forms. There is a difference between MYNE and THINE. Overall the percentage of THINE, relatively speaking, is greater. For demonstration purposes here, the areas of first and second person forms are shown as equally large. There are of course many more first-person forms than second person forms. I just want you to be aware of that.

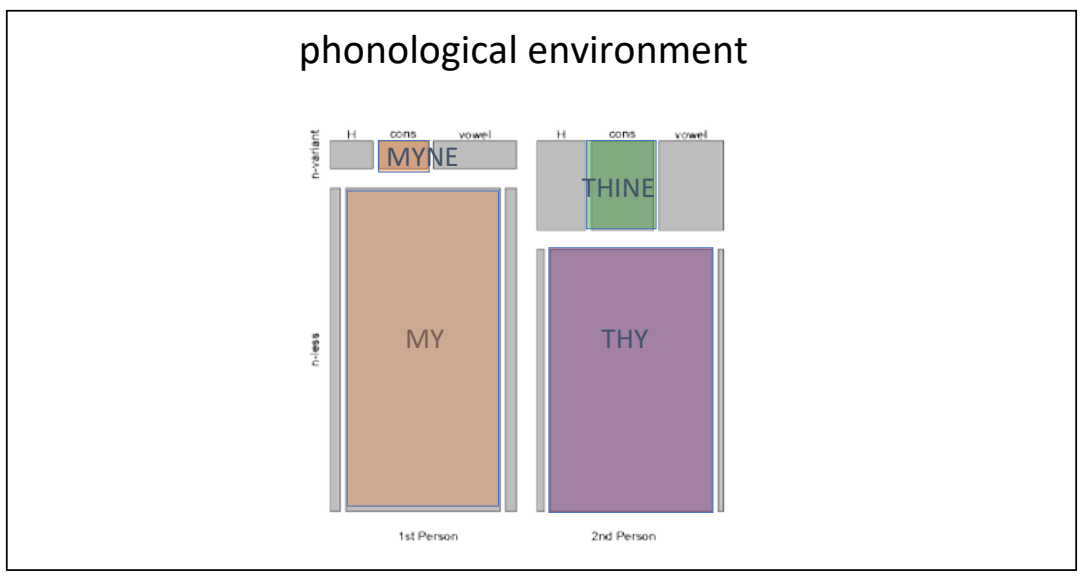

FIGURE 10

The crucial information in this graph concerns the differences in the way in which the four areas are internally partitioned. What you see is that $m y$ and thy mostly occur before words that start in a consonant. This is simply because adjectives and nouns, the elements that follow possessive determiners, have a tendency to start in a consonant. With myne and thine, consonants are underrepresented while vowels and H'es are overrepresented. The question now is, are vowels and H'es equally overrepresented across first and second forms, or is there a difference?

When we look at the upper parts of the graph, it appears that first person forms have a slightly bigger preference for prevocalic environments. If you compare the brown block against the green block, then the brown block is wider, but the effect is not very pronounced. Likely, there is no difference 


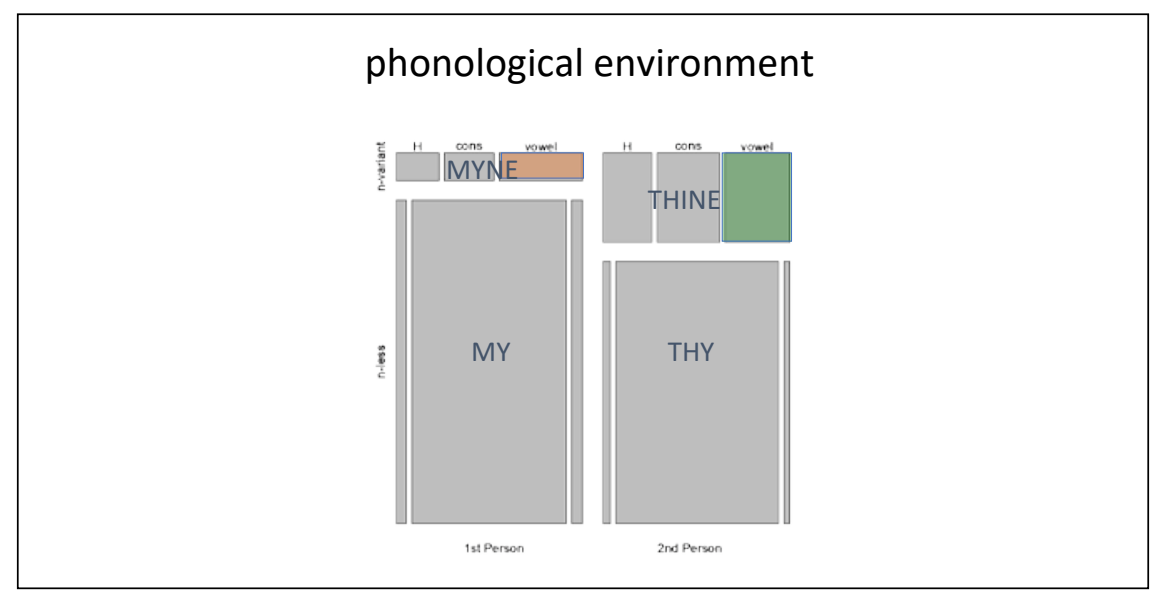

FIGURE 11

\section{stress}

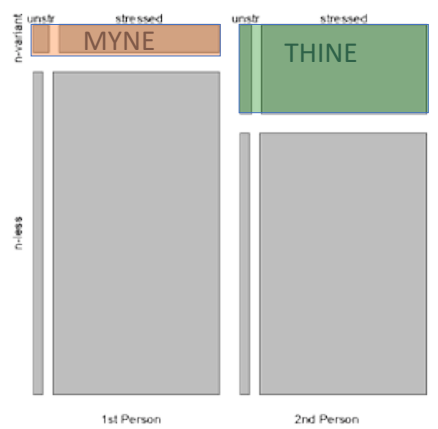

FIGURE 12

between MYNE and THINE with regard to the first variable of the phonological environment.

What about stress? Here, we have the same kind of mosaic design. This time, the partitioning contrasts unstressed and stressed beginnings of the following word. You see that in most cases, the following syllable is actually stressed. If we look at the upper parts of the graph, both MYNE and THINE show a slightly larger proportion of unstressed following syllables. With MYNE, this preference might be just a tiny bit stronger, but again, there is definitely not a strong effect.

Things look different when we come to formality. For the mosaic for formality, what is striking is that the n-variant shows a greater ratio of examples from 


\section{formality}

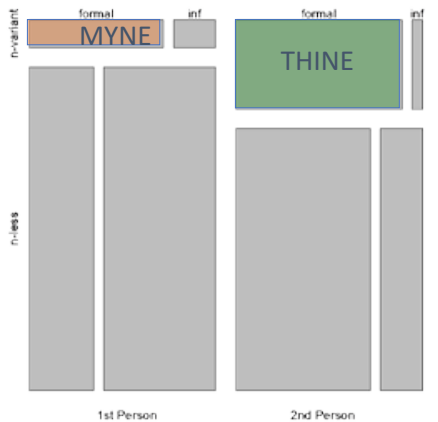

FIGURE 13

formal genres. With MYNE, formal examples are colored in brown. For THINE, which are shown in green, there are many more examples in formal genres. There is a straightforward explanation for this effect. THINE hardly ever occurs in informal texts, because the alternative form YOUR develops in this period, from which these data are taken. The rise of YOUR definitely interferes with the usage of THINE and THY. But it does not interfere with MYNE and MY. Here we have suggestive evidence to the effect that first and second person forms might in fact have developed in different ways. According to the variable of formality, MYNE and THINE do likely not develop in identical ways.

I would like to come to gender. This mosaic plot shows an interesting but somewhat minor difference. Note that female users are relatively less likely to use THINE in their writings. You see that females have this very thin strip of THINE, shown in green. They use MYNE a little more in comparison. It is true that most female writers that are in the data come from later periods of the corpus. This could be an artifact, but that kind of artefact can be addressed in the statistical analysis that I am about to talk about.

Lastly, it remains to be discussed whether the effect of priming is different across first and second person forms. This is the last graph of this kind. Here, it is evident that the $\mathrm{n}$-variant benefits from priming. You see that the areas for $\mathrm{n}$ primed are wider in the upper parts of the graph. In the lower parts, in the strips that we see for the n-less variant that are colored in brown and purple, they are more narrow. Primed examples account for a bigger share of the overall number of examples than in the n-less examples. The lesson from that is clear actually. You do not need priming to get $M Y$, but priming may help you to get MYNE. When there is a form that it is on its way out, you are generally less 


\section{gender}

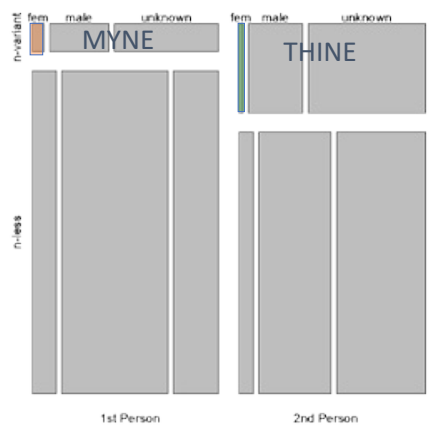

FIGURE 14

\section{priming}

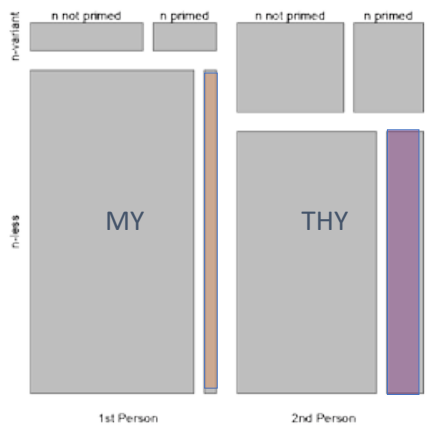

FIGURE 15

likely to use it except when you've recently heard it. That is an opportunity to remember it and then come back to use that old variant. Is this effect different across the two persons? Probably not. It looks very similar, but again, this is something for the regression analysis to figure out.

If we now come back to the three questions one more time, we can try to formulate a few conjectures. Which of the factors have a reliable effect? We're fairly certain that time, the following segments, stress, person, gender, priming, and the collocates that we see would have an effect.

Did their effect stay constant over time or did they change? We hypothesize that there would be changes with regard to the following segment. That effect looked like it would be time-sensitive. Also, the effects of stress and collocate 
frequency, which were non-uniform across time, would lead us to expect this kind of interaction effect.

Did myne and thine change in the same way, at the same time? There are some minor differences between myne and thine with regard to formality, gender and priming. I fitted a logistic regression model to the data that tests for the respective main effects and interactions.

The statistical modeling allows us to determine which factors make a difference at what time. The method I used is known as binary logistic regression. That is a technique that can be used to investigate the variables that influence a binary choice either in an experiment or in natural language use from corpora. In language, binary choices can be seen as two ways of saying the same thing. Let me take an example that I haven't used so far. A phonological binary choice in English is exemplified by yod-dropping. Speakers can say "She is such a good /stju:dənt/" with a /j:/ glide in it, or say "She is such a good /stu:dənt/" without that glide. Another binary choice would be the alternation between be going to and will, for example I do not know what I am going to do vs. I do not know what I will do. There is the dative alternation, i.e.John gave Mary the book and John gave the book to Mary.

What do you analyze in such a design? The basic question, in all of these cases, would be whether we can explain why a speaker sometimes does one thing and sometimes another. What are the variables that can explain this behavior? The explanatory variables can be linguistic (language-internal) or they can be non-linguistic (language-external).

With regard to yod-dropping, your region of residence plays a role. Your age might play a role. Your gender or your level of education could come in. All of these are language-external factors. For the dative alternation, i.e. John gave Mary the book and John gave the book to Mary, there is a host of factors that have been studied that contribute to the alternation. Pronominality is one such factor. Whether the recipient is expressed with a pronoun, John gave her the book, or a full noun phrase, John gave the woman the book, plays an important role. If the recipient is pronominal, then there is a preference for the ditransitive, as opposed to the prepositional dative. There are even some hard constraints, such as the animacy of the recipient. I can say "John threw his keys to the floor". I cannot say "John threw the floor his keys". That would imply that the floor is animate and is waiting to catch the keys that John is throwing. Inanimate recipients bias speakers very strongly and consistently towards the prepositional dative. Finally, the definiteness of the theme is important. Whether I have an indefinite noun phrase like "John gave Mary a letter" or a definite noun phrase "John gave Mary the letter", that makes a difference, not that big of a difference, but a measurable difference. Indefinite noun phrases are preferably placed at 
the end. That is why there is a preference for the ditransitive. With regard to the dative alternation, we have these language-internal factors of indefiniteness, animacy, and pronominality . All of those are language-internal, concerning morphology, semantics, and pragmatics, respectively.

Similar to the alternations I just presented, the case between myne and my features one linguistic variable which we call the dependent variable, which is binary and categorical, that is, a choice between A and B. A and B are called the "levels" of the dependent variable. Then there are several explanatory factors, language-internal and language-external. They can be categorical, such as accusative vs. dative, or pronominal vs. nominal. They can also be continuous, as in length in words or word frequency. All of these variables can be integrated into the analysis.

You employ a binary logistic regression generally in order to obtain answers to the following questions: Which explanatory factors have an influence on the dependent variable? How strong are the respective variables in their influence? How well do the variables explain the variation that we observe?

What kind of data can enter the analysis? In corpus-based research, you would have to retrieve all occurrences of language use in a given corpus where speakers actually have the choice between A and B. For the case of the /stju:dənt/ and /stu:dənt/ alternation, you would have to find all words where / $\mathrm{u}$ :/ can be preceded by a glide $/ \mathrm{j} /$. With the dative alternation, you would have to find all instances of the ditransitive and all instances of the prepositional dative.

Coming back to my and myne, here we would collect all instances in which writers use a possessive determiner and have the choice between using either the conservative n-variant or the progressive n-less variant. What does the regression do with that data? It calculates a formula that allows you to predict for new examples, from a different corpus, how likely it will be that speakers choose the n-less variant rather than the n-variant. If in a large database of examples, we find an example such as the daies of my life, then how likely is the n-less variant, given its date of production, given its phonological environment, given the gender of the writer and given the formality or informality of the genre?

There is one complication that I need to discuss. Sometimes variables may interact. Several explanatory factors can conspire with each other, which yields an effect that is different from what we would call a simple main effect. A main effect obtains when an explanatory factor always has the same effect on the choice between A and B. In an interaction effect, by contrast, an explanatory factor has an effect on the choice between A and B, but this effect depends on another variable. 
Let me give you an example. We're interested in speakers' use of polite or direct pronouns in a corpus. The dependent variable would be a binary choice: Does the speaker use of a polite pronoun or a direct pronoun? The explanatory factors that we take into account are age, gender and formality. A main effect of gender would be that female speakers have a bias towards the use of polite pronouns. An interaction effect would be that age and gender conspire. If gender interacts with age, that means that old female speakers are biased towards polite pronouns, but young female speakers are not affected in the same way.

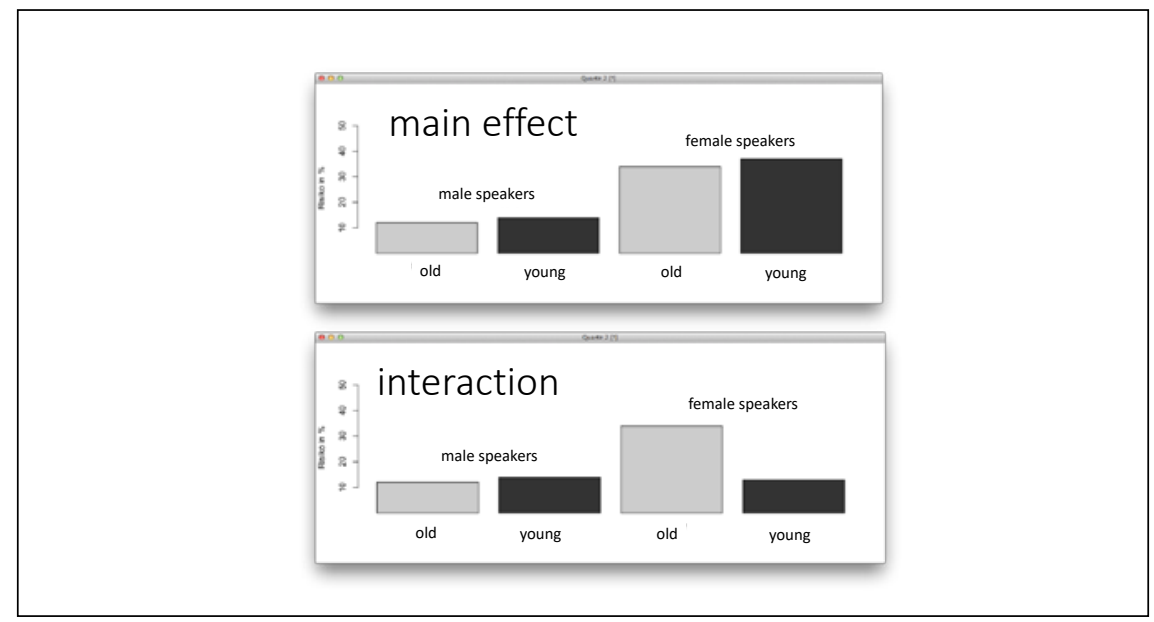

FIGURE 16

I try to visualize that on this slide. The upper graph shows a main effect. You compare male and female speakers across two different age groups. It turns out that male speakers pattern together. Age does not play a role, as young and old males are alike, and young and old females are alike. This would be a main effect of gender. An interaction effect would be if old female speakers have a preference for polite pronouns, but young female speakers do not, and they pattern exactly like the old and young male speakers.

This graph shows a potential interaction effect in the use of myne and my. The interacting variables are stress and time. When we look at this graph, right stress has an effect, but sometimes it is strong, sometimes it is not. We should therefore test whether there is an interaction between time and stress.

Here I am coming back to one of the mosaic graphs with gender. Gender has an effect, so that females use more n-less forms. They are more progressive, but we might ask whether this effect is equally strong for first person and second person forms. We could test whether there is an interaction between gender and person. 

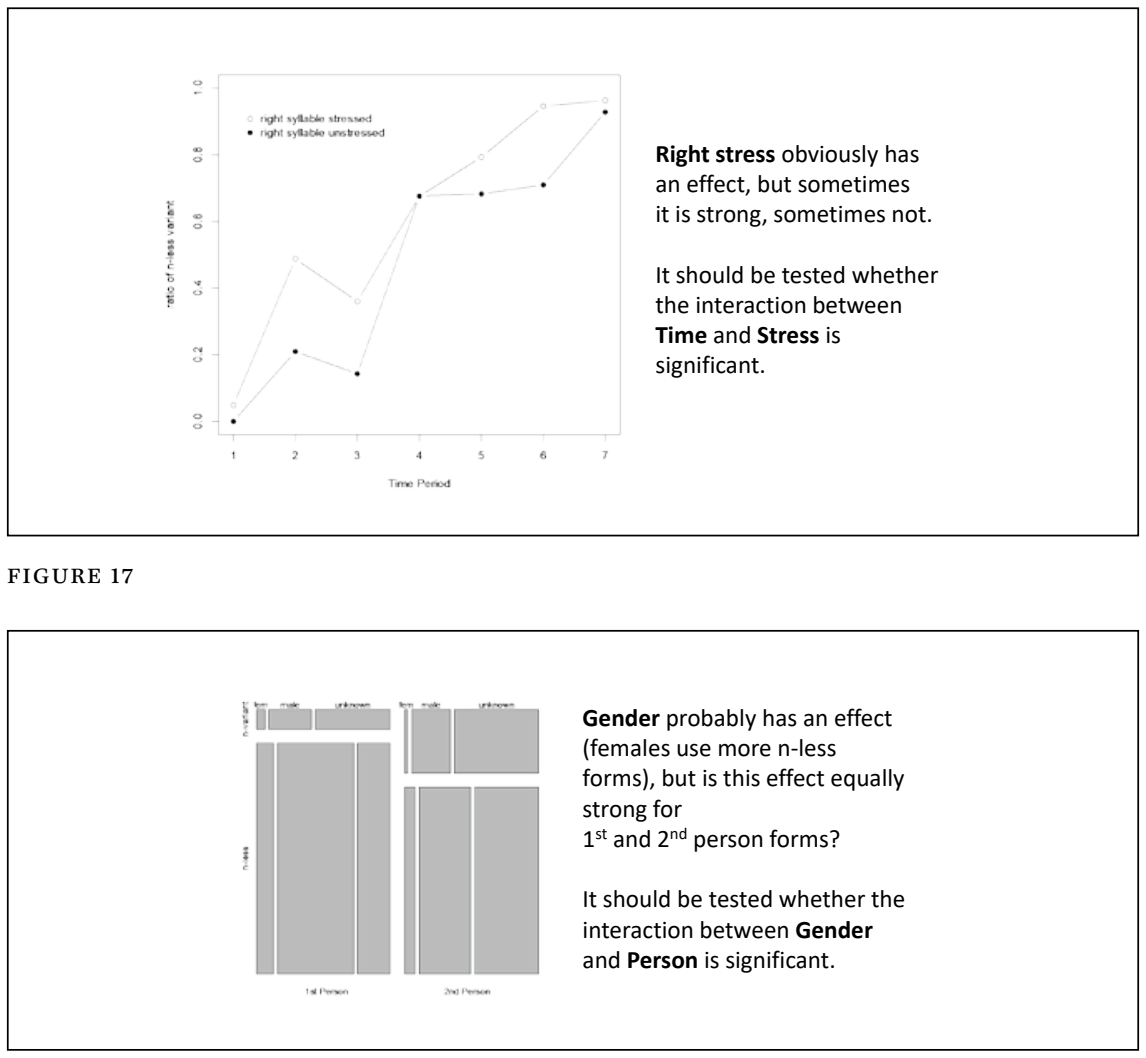

FIGURE 18

Which factors make a difference at what time? I fitted a regression model in which I tested for main effects of all of the explanatory factors that I mentioned before. I tested for a selected range of interaction effects. For time and the following segment, we can be fairly sure that there is an interaction, because we observed that the effect of the phonological environment was time-sensitive. For time and stress, we saw that the effect of stress is not uniform across time. The same goes for time and collocate frequency. I also tested for interaction effects between person and formality, person and priming, and person and gender. Since I used mixed-effects regression modeling, I was able to include the authors and the respective corpus files as random factors.

What came out? There are main effects for time, for the following segment, for stress, for priming, for gender and for collocate frequency, meaning that only two variables that were included originally turned out to be nonsignificant, and those are person and formality. The non-significance of person means that there is no evidence for a separate generalization for second and 
first person possessive determiners. The non-significance of formality means that the use of possessive determiners is not reliably different across formal and informal texts. I ran another analysis in which I excluded those variables that did not have a significant effect.

The revised analysis obtains significant effects for the variables that mattered already the first time around. There are several interaction effects that the model included as significant. There is an interaction between time and stress, so that the effect of stress becomes weaker over time. There is an interaction of time and collocate frequency. The effect of collocate frequency is significant but unstable. For the interaction between time and the following segment, a following consonant always increases the likelihood of the n-less variant, but the effect is strongest in the early periods. The technical indicators tell us that model provides a useful summary of the data.

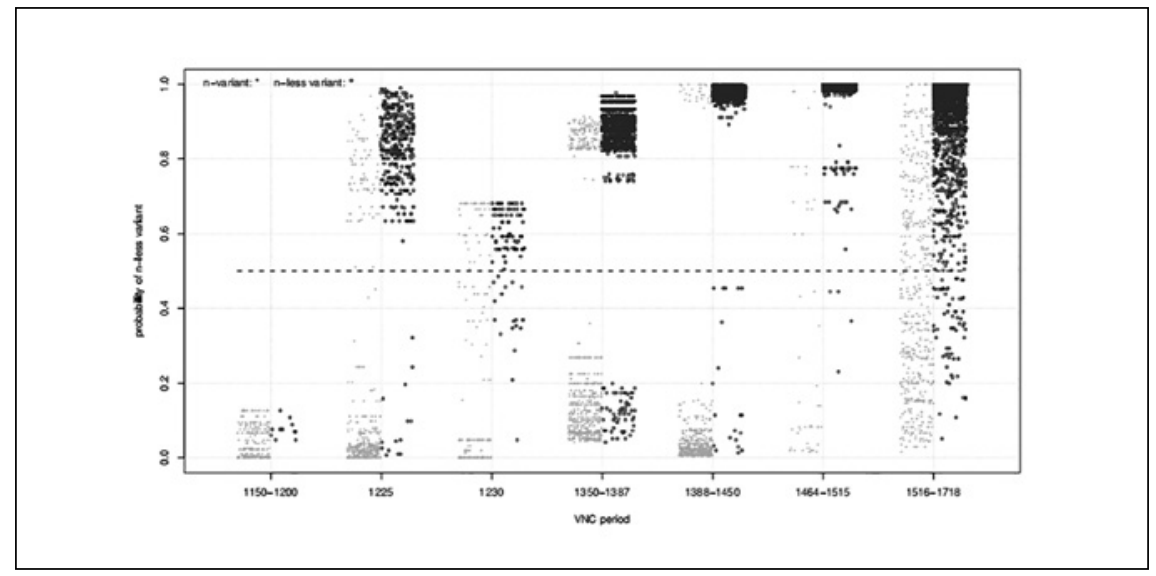

FIGURE 19

I am sorry that I am bombarding you with strange-looking graphs in this lecture, but I would like to give you another quick look under the hood of the regression model. What you see in this graph shows you how well or how poorly the model discriminates between examples of the n-variant and the n-less variant.

The grey little specks you can see on this slide are examples of the n-variant. The graph also shows examples of the n-less variant, the new variant. Those are shown as black little circles. The graph has a $y$-axis. If a data point appears up high on the y-axis, that means that the model returns a strong prediction that we are looking at a modern n-less variant. If the model places a data point further down, near zero, that means that the model predicts an n-variant. Ideally, we would have all the grey spots down in the lower half, and we would have all 
the black circles in the upper half. Ideally, we would want a very crisp and clear distribution that this half down here is all grey, that half up there is all black. What you see is that this is not $100 \%$ the case.

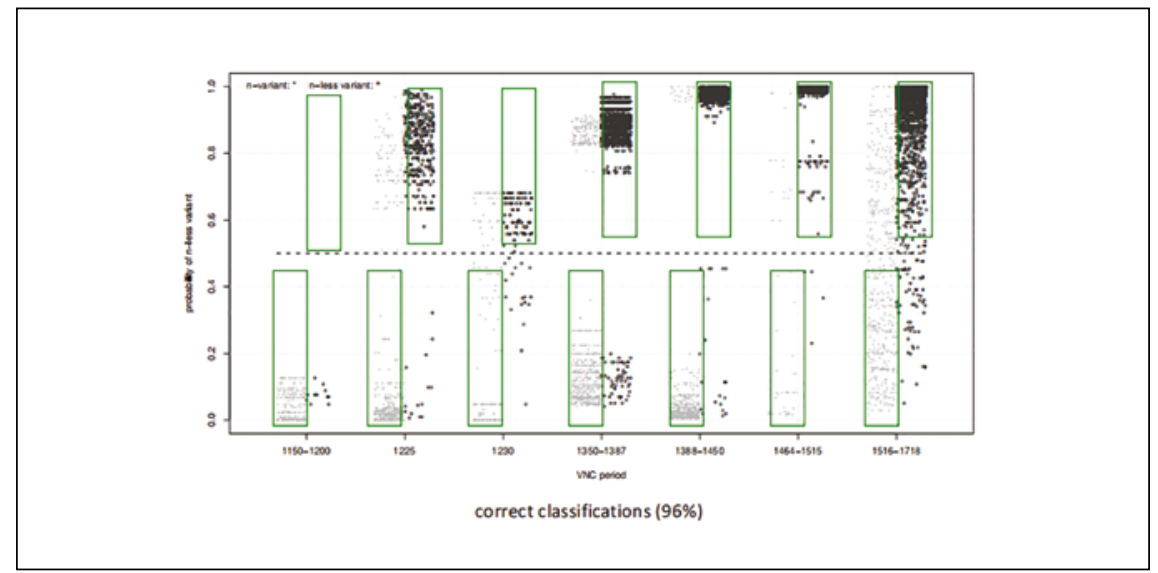

FIGURE 20

To rephrase this, in this version of the graph, I have put all of the correct predictions that the model makes into green boxes. If we have dots in a green box, that means the model has made the right assessment. For example, in the last period, the model predicts for the overwhelming majority of n-less forms correctly that they are n-less. There are only a few in the lower half that are misclassifications. That is actually the reason why I want to show you this graph. We want to figure out where and why the model fails. Models are imperfect, and we want to learn a little bit about why and when they fail.

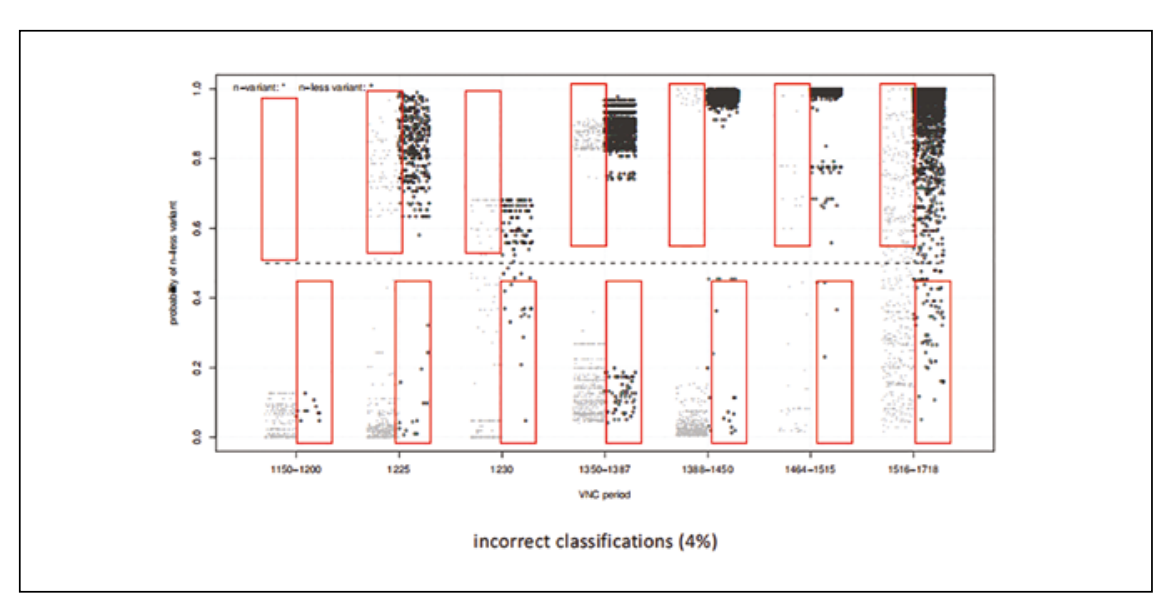

FIGURE 21 
This slide shows the misclassifications in red boxes. In the first period, there are a few modern forms, but the model misclassifies them and gives very confident predictions that these are n-forms. In the second period, we observe the same thing, but notice that there are also many $n$-forms which the model classifies mistakenly as n-less, that is what you see in the red box in the upper half. Going further, we see that there are lots of forms that are misclassified. But globally, the model makes the right predictions most of the time. Let's look at some of the misclassifications in more detail.

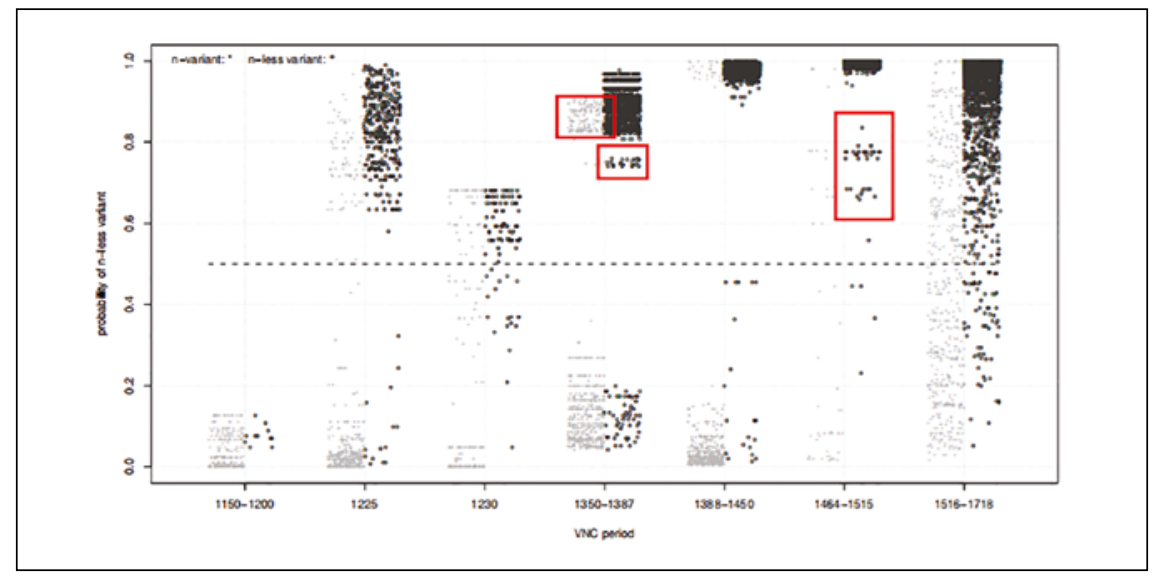

FIGURE 22

For example, what is going on here in the fourth period? There is a set of examples classified as n-less, but they do in fact have an n. It turns out that in this period, the model overestimates the discriminative power of the following segment. If a form is followed by a word beginning in a consonant, such as my brother or my friend, then the form is given a high likelihood estimate for the modern variant. This can be considered as an honest mistake that the model makes. The following segment used to be a very powerful discriminant variable in the earlier periods, but in the fourth period, that importance is decreasing. The factor is becoming less predictive, less strong.

If we are looking at the sixth period, there are a number of examples that the model correctly classifies as n-less, but not very confidently so. The red box in the sixth period shows correct classifications, but the model is less confident of that than with other data points that are further up. What characterizes the examples in the red box? Those are examples before vowels and H'es. These phonological environments are predictive of an $n$-form, so the model classifies them as n-less with less confidence. Similarly, the black circles in the fourth 
period that are in the red box, they are not misclassifications, but again the model's predictions are less confident. These examples are not followed by a stressed syllable, as for instance my confession.

To make a long story short, this graph allows you to look qualitatively at the statistical analysis, which can otherwise be a black box. Statistics can and should be a tool to guide you towards the examples that are relevant and that you want to look at more closely. The method further allows you to perform cross-validation. The main point of that is to verify how good the analysis is by confronting it with unseen data from a different corpus. In this case, the model actually succeeds in classifying that data rather well. The resulting analysis yields the same significant predictors and interactions.

Summing up, I think that there are issues of theoretical interest in Construction Grammar that can be analyzed in a very satisfying way with methodologies that we borrow from frameworks such as variationist sociolinguistics. In this particular case, I was after the question of whether two forms develop in identical or different ways. I hope to have shown that the similarities between myne and thine greatly outweigh the differences. All in all, that would suggest that their development constitutes one single constructional change.

The change from myne to my is a case of constructional competition that has gone to completion. The propagation of the new variant has led to a complete substitution of the old variant. This kind of propagation can be shown to relate to different factors, both language-internal and language-external. We have a very good idea of what caused competition at various points in time. The quantitative techniques that I have applied here can help us uncover how propagation actually proceeds. Different factors influence competition at different times with different strengths. That is the conclusion that I would like to leave you with today. Thank you for your attention. 